\title{
Viewpoint on Relief of COVID-19 Burden in India by Administration of System to Break the Chain of SARS-CoV-2 at the Grass-roots Level
}

\author{
Bhushan P. Bhusare ${ }^{1}$ and Vasudeo P. Zambare ${ }^{2 *}$ \\ 'Department of Botany, Savitribai Phule Pune University, Pune, Maharashtra, India \\ ${ }^{2}$ R\&D Department, Om Biotechnologies, Nashik, Maharashtra, India \\ Email:vasuzambare@gmail.com
}

\begin{abstract}
During 2020, the first wave of COVID-19 pandemic hit badly the Indian subcontinent very surprisingly. Indian Government and every citizen of India have attempted many more strategies on damage control of pandemic in terms of human lives, population, health, and socio-economic impacts. Second wave have battered us significantly tanks to our hubris and callousness. In anticipation of the potential third wave, the system has developed a massive but at grassroots level pragmatic and strategic roadmap for sensitizing the policy maker and coordinators. The existing infrastructure and manpower utilization could be the best, eco-friendly and the most effective way to break the chain of SARS-CoV-2. The infrastructure includes Government schools and manpower work as an administrative system which includes elected MLAs, medical doctors, village head (Sarpanch), village council's elected members and local people. Managing this system at grass root level could be the best and effective way to break the chain of SARS-CoV-2 in all states of India. Additionally special attention is given to children of high risk area to avoid the third wave of COVID-19.
\end{abstract}

Keywords: COVID-19; Village Council; SARS-CoV-2; India; Administration system; Strategies

\section{Pandemic Situation and Standards Management in India}

The year 2020 was found to be the worst year in Indian history due to pandemic situation which badly damaged the human lives. The COVID-19 cases are exponentially increasing day by day which is an alarming signal for our survival. It has been very difficult to comprehend the actual affected cases in India as well as the health conditions of suffered patients was very hard to apprehend. As of May 12, 2021, more than 20.3 million confirmed cases of COVID19 had been reported, with an increased trend of 3,48,421 new cases in a day and total death cases of 2,54,197. Due to theses day to day cases and fully loaded hospitals, a deadly fear is developed among the frontline healthcare workers as well every individuals. Additionally, an increasing demand of hospital bed, oxygen deficit conditions including ventilators and other necessities showed negligence of peoples towards its precaution. In short, doing 2021 second wave of COVID-19 have battered us significantly tanks to our hubris and callousness. India is comparing about the COVID- 19 vaccination but $\approx 13 \%$ of the population is vaccinated so far. By understanding the Indian system, the whole vaccination system has some shortfalls such as COVID-19 testing and its traceability ${ }^{[1-3]}$. These strategies are especially important for prevention of successive waves of outbreaks when social distancing measures are relaxed during schools and businesses reopening ${ }^{[4-7]}$. The third wave looks imminent with patent fangs that is likely continue the disruption of our normal lives in future

${ }^{*}$ Author for correspondence 
including small children. Thus, the children population should be monitored and precautionary considered on the topmost priority ${ }^{[8]}$. The symptomatic criteria to check the COVID-19 in children are with the common symptoms of cough, fever and breathing problem which are as usual like adults. However, a Chineese study reported a data of COVID-19 infected children with positive RT-PCR test of SARS-CoV-2 infection observed the signs and symptoms of $48.5 \%$ cough, $46.2 \%$ pharyngeal erythema, $41.5 \%$ fever, $28.7 \%$ fast breathing, $8.8 \%$ diarrhea, $7.6 \%$ rhinorrhea, $7.6 \%$ fatigue, and $6.4 \%$ vomiting ${ }^{[9]}$. Thus, special attention has to be given on children from designated hotspot or confirmed areas of COVID-19 cases. In addition to this narrow down scrutiny of children whose parents had been affected by COVID-19 earlier, as it is the direct or indirect way of risk of possible infections in children ${ }^{[10]}$.

Thus, for mitigation the impact of third wave, every citizen must have to learn from the past experience and prepared ourselves with more preventive measures. In anticipation of the potential third wave, there is a need of pragmatic and strategic roadmap for policy maker and mass community at grass-roots level. The present opinion proposing a binary key system to mitigate SARS-CoV-2 outbreaks: first based on elected MLAs who have to arrange the money or arranged funds from government to build the COVID care centre; second is based on utilization of the available infrastructure such as primary schools. The second one is always advantageous option as it saves the infrastructure cost however, in first one infrastructure building cost, its maintenance cost and time are involved which could be a very costly option. In this pandemic situation a prompt action with available resources is necessary and this kind of work was very superficially executed by Mr. Nilesh Dnyandeo Lanke (MLA of Parner constituency, Ahmednagar, Maharashtra, India). He has created a new milestone and showed his presence of mind for the benefits of citizen. Thus, each MLA has to take lead and tackle the pandemic situation with following roles and responsibilities. Elected MLAs from their constituency can perform an important role in government agenda to control the community spread and break the chain of COVID-19 with following steps and the flowchart as shown in Figure 1.

1. To document data of active COVID patients (including Male, Female or Children) from different villages of their constituency

2. To use primary school as COVID care centre instead of creating new ones.
3. To clean the school rooms and toilet facilities neatly with proper ventilation system.

4. To arrange all necessary medical equipment and medicine for COVID-19 treatment.

5. To equipped some beds with oxygen and ventilator system for critical and emergency use.

6. To create a special room for corona testing (quick test of rapid antigen Test and confirmatory RT-PCR test ${ }^{[11]}$.

7. To manage medical doctors and staff, their roles and responsibilities and visiting schedule.

8. As this programme is for grass root level, some of the village people must be trained for handling any situation in case of any urgency.

9. These trained people can be used as an alternative for medical staff (helper or nursing staff) and their duties also be made on rotational basis i.e. for eight hour with different shift (6:00 am to 2:00 pm;2:00 pm to $10: 00 \mathrm{pm} ; 10 \mathrm{pm}$ to $6: 00 \mathrm{am})$. After every week the shift will be changed for each staff.

10. To give responsibility to village head (Sarpanch) and other elected village council members for constant surveillance of COVID care centre and strictly prohibit the entry for others in or near the centre.

11. The entry gate of the centre must secure with one of the security guard, one who strictly prohibit the entry for other village people (people instead of village head, village council members and COVID 19 trained staff). Proper identity card of staff must be checked at the entry point.

12. Once person entered with main gate, his temperature (with the help of thermometer) and Oxygen pulses (with the help of Oxymeter) should be checked by another trained person. If found suitable then only permit to enter otherwise do further medical test or don't allow that person.

13. To visit local village doctors to the centre and in emergency condition all doctors have to reach the centre immediately and handle the situation.

14. To give authority to medical officer of government PMC (Primary Medical Centre) for emergency situation handling in consultation with doctors and nursing staff.

15. It is believed that in COVID-19, comorbidities (hypertension or diabetes mellitus) have an increasingly rapid and severe progression, often leading to death. There should be the complete record 


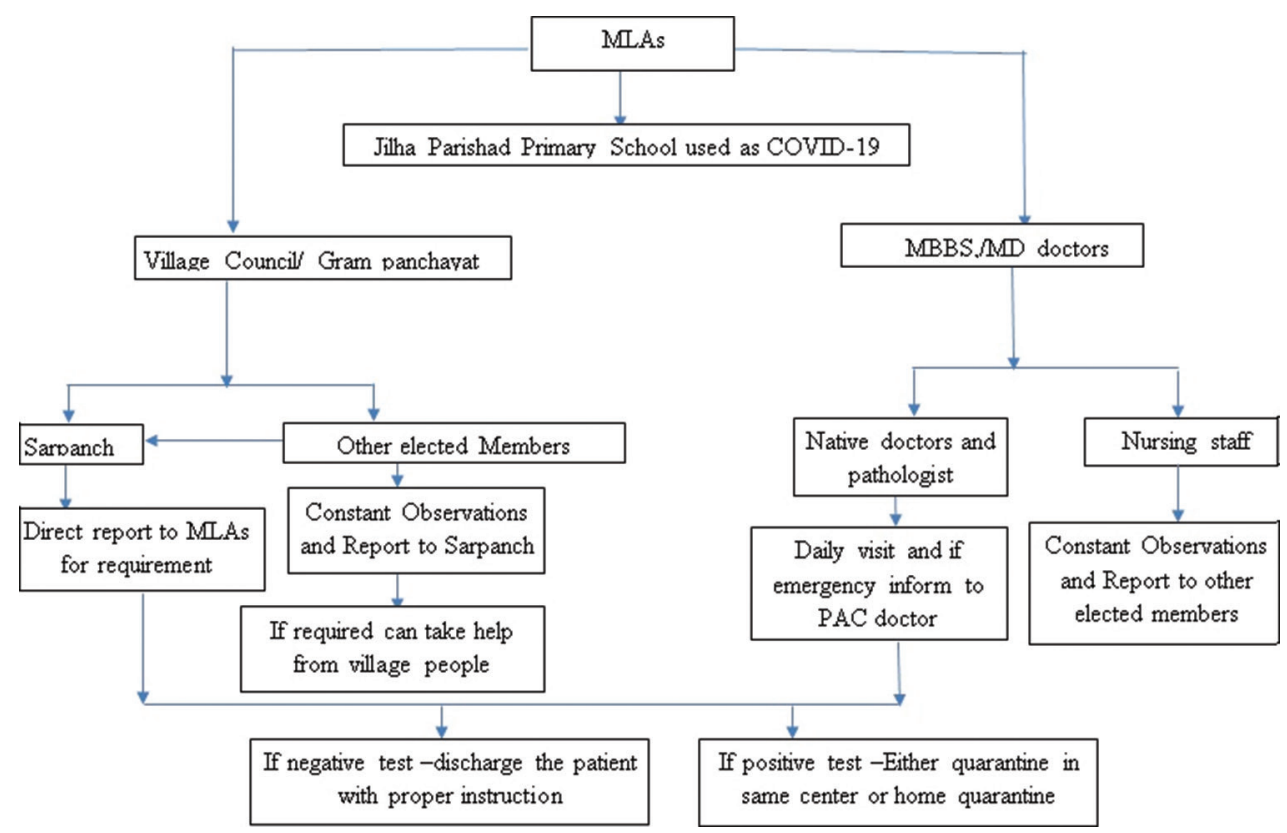

Figure 1. Ground level strategic plan for braking of COVID-19 infection chain.

of the population having co-morbidities and special attention can be given to them.

16. Proper consultations are also necessary to these patients for precautions to avoid getting further infection with SARS CoV-2, as they usually have the worst prognosis.

17. To make arrangement of food for COVID-19 patients by elected village council members and other socially influencing people.

18. To make quarantine facility for COVID-19 positive patients and must be tested time to time by RT-PCR test.

19. To provide proper instructions on food intake, medication and aware about the precautionary measures to patient.

\section{Advantages of Key Systems}

For SARS-COV-2, it has been very important to trace the source of infection because there is a high probability that infected person can spread the infection person to person or through mass gatherings. Thus to stop or break this chain from it has been very important to trace the source ${ }^{[12]}$. This chain break could be achieved by quarantine the infected people at native places which will avoid the transmission of the infection ${ }^{[13-16]}$. Our earlier studies also focused on some of the basics of COVID19 in terms of its persistence, precautions, diagnosis, challenges ${ }^{[17]}$ as well as its overall impact of environment and personals ${ }^{[18]}$. Thus, the proposed opinion, suggests a highly specific strategy for effective breaking the chain followed by an effective awareness program. These strategies could be guidelines for individual person for handling and managing the pandemic situation with minimum risk of infections and at very low cost.

\section{The Path Forward}

For implementation of such system has lot of ambiguity and lack of confidence of control of infectious diseases. It is obvious, because of metal pressure every individual always thinks about the better option. All systems have its own advantages and disadvantages and need to understand it in the pandemic situation with a calm mind. Many more strategies has been proposed by many societies, scientists and governmental agencies but the proposed strategy could be a progressive and more effective from grassroots level to balance population of different location, regions and state with available resources. Most importantly, it will avoid the extra financial burden of the governments and create a future roadmap of handling of any national calamities.

\section{Declaration of Patient Consent}

Patient's consent not required as there are no patients in this study. 


\section{Financial Support and Sponsorship}

Nil.

\section{Declaration of Interests}

Authors declared no competing interests.

\section{References}

1. Salathé M, Althaus CL, Neher R, Stringhini S, Hodcroft E, Fellay J, Zwahlen M, Senti G, Battegay M, Wilder-Smith A, Eckerle I, Egger M, Low N. COVID-19 epidemic in Switzerland: on the importance of testing, contact tracing and isolation. Swiss Med Wkly 2020; 150: w20225. doi: 10.4414/smw.2020.20225.PMID: 32191813.

2. Steinbrook R. Contact tracing, testing, and control of COVID-19- learning from Taiwan. JAMA Intern Med 2020;180:1163-64.doi:10.1001/jamainternmed.2020.2072. PMID: 32356871.

3. Sun K, Viboud C. Impact of contact tracing on SARSCoV-2 transmission. Lancet Infect Dis 2020; 20: 876-77. doi: 10.1016/S1473-3099(20)30357-1. PMID: 32353350; PMCID: PMC7185949.

4. Aleta A, Martín-Corral D, Pastore Y Piontti A, Ajelli M, Litvinova M, Chinazzi M, Dean NE, Halloran ME, Longini IM Jr, Merler S, Pentland A, Vespignani A, Moro E, Moreno Y.Modelling the impact of testing, contact tracing and household quarantine on second waves of COVID-19. Nat Hum Behav 2020; 4: 964-71. doi: 10.1038/s41562-0200931-9. PMID: 32759985; PMCID: PMC7641501.

5. Giordano G, Blanchini F, Bruno R, Colaneri P, Di Filippo A, Di Matteo A, Colaneri M.t al. Modelling the COVID-19 epidemic and implementation of population-wide interventions in Italy. Nat Med 2020; 26: 855-60. doi: 10.1038/s41591-020-0883-7. PMID: 32322102; PMCID: PMC7175834.

6. Koo JR, Cook AR, Park M, Sun Y, Sun H, Lim JT, Tam C, Dickens BL. Interventions to mitigate early spread of SARSCoV-2 in Singapore: a modelling study. Lancet Infect Dis 2020; 20: 678-88. doi: 10.1016/S1473-3099(20)30162-6. PMID: 32213332; PMCID: PMC7158571.

7. Panovska-Griffiths J, Kerr CC, Stuart RM, Mistry D, Klein DJ, Viner RM, Bonell C.Determining the optimal strategy for reopening schools, the impact of test and trace interventions, and the risk of occurrence of a second COVID-19 epidemic wave in the UK: a modelling study. Lancet Child Adolesc Health 2020; 4: 817-27. doi: 10.1016/
S2352-4642(20)30250-9. PMID: 32758453; PMCID: PMC7398659.

8. Benfer N, Spitzer EG, Bardeen JR. Efficacy of third wave cognitive behavioural therapies in the treatment of posttraumatic stress: A meta-analytic study. J Anxi Disord. 2021 Jan 18:102360. doi: 10.1016/j.janxdis.2021.102360. PMID: 33485102.

9. Sankar J, Dhochak N, Kabra SK, Lodha R. COVID-19 in children: clinical approach and management. Ind J Paediat. 2020 Jun; 87(6):433-42. doi: 10.1007/s12098-020-03292-1. PMID: 32338347 ; PMCID: PMC7183927.

10. Sanyaolu A, Okorie C, Marinkovic A, Patidar R, Younis K, Desai P, Hosein Z, Padda I, Mangat J, Altaf M. Comorbidity and its impact on patients with COVID-19. SN Compr Clin Med. 2020 Jun 25:1-8. doi: 10.1007/s42399-020-00363-4. PMID: 32838147; PMCID: PMC7314621.

11. Patankar RS, Zambare VP. Development of RT-PCR Based Diagnosis of SARS-CoV-2. In: Biotechnology to Combat COVID-19, Megha Agrawal and Shyamasri Biswas(eds.), IntechOpen, doi: 10.5772/intechopen.96823 (Publication date: March $16^{\text {th }} 2021$ ).

12. Kennedy-Shaffer L, Baym M, Hanage WP. Perfect as the enemy of good: tracing transmissions with low-sensitivity tests to mitigateSARS-CoV-2 outbreaks. The Lancet Microbe 2021; e219-24. doi: 10.1016/S2666-5247(21)00004-5. PMID: 33748803; PMCID: PMC7954468.1

13. Adam DC, Wu P, Wong JY, Lau EHY, Tsang TK, Cauchemez S, Leung GM, Cowling BJ.l. Clustering and superspreading potential of SARS-CoV-2 infections in Hong Kong. Nat Med 2020; 26: 1714-19. doi: 10.1038/ s41591-020-1092-0. PMID: 32943787.

14. Hodcroft EB. Preliminary case report on the SARS-CoV-2 cluster in the UK, France, and Spain. Swiss Med Wkly 2020; 150:9-10. doi: 10.4414/smw.2020.20212. PMID: 32227799.

15. Endo A, Abbott S, Kucharski AJ, Funk S. Estimating the overdispersion in COVID-19 transmission using outbreak sizes outside China. Wellcome Open Res 2020; 5: 67. doi: 10.12688/wellcomeopenres.15842.3. PMID: 32685698; PMCID: PMC7338915.

16. Al-Tawfiq JA, Rodriguez-Morales AJ. Super-spreading events and contribution to transmission of MERS, SARS, and SARS-CoV-2 (COVID-19). J Hosp Infect 2020; 105:111-112. doi: 10.1016/j.jhin.2020.04.002. PMID: 32277963; PMCID: PMC7194732.

17. Bhusare BP, Zambare VP, Naik AA. COVID-19: Persistence, precautions, diagnosis and challenges. J Pure Appl Microbiol 2020;14: 823-829. doi: 10.22207/JPAM.14.SPL1.19

18. Zambare VP. Covid-19 to curb positive climate and negative recession. J Tropical Life Sci; 2021; 11:119. doi: 10.11594/jtls.11.01.15 